\title{
AN ERGONOMIC APPROACH TO DESIGN HAND ToOl For SCREen TeXtile Printing
}

\author{
M. L. Meena and G. S. Dangayach \\ Department of Mechanical Engineering, Malaviya National Institute of Technology \\ Jaipur, India
}

\begin{abstract}
The musculoskeletal disorders are the most common work-related health problems in India, affecting thousands of workers. Typically, musculoskeletal disorders affect the low back, neck, shoulders and wrist pain.This study was conducted in screen printing textile industry of Jaipur, Rajasthan, Indiato determine the occurrence of upper limb problems associated with hand tool design, investigate the existing hand tools currently used in screen printing, and redesign hand tool based on anthropometric dimensions and ergonomic principles. In this study, 300 workers were participated and a questionnaire survey consisting of personal details, anthropometric dimensions of hand and Nordic Questionnaire for musculoskeletal disorders has been done.In 64\% of the cases, the new hand tool was evaluated as little better or better and the comfort was improved.
\end{abstract}

\section{KEYWORDS}

Ergonomic principles, Hand tool, Musculoskeletal disorders, Screen printing.

\section{INTRODUCTION}

Indian textile industry largely depends upon the manufacturing and export of textile. India earns $27 \%$ of its total foreign exchange through textile exports. Further, the textile industry also contributes nearly $14 \%$ of the total industrial production of the India. It also contributes around $3 \%$ to the gross domestic product of the country [1]. Textile printing was very famous in across world, from the 12th century, and was generally used. Textile printing was firstly introduced into England in 1676 by a Frenchrefugee who opened works, on the banks of the Thames near Richmond. In Germany, textile printing was also probably started before it spread to England, towards the end of the 17th century, the district of Augsburg was celebrated for its printed linens, a reputation not likely to have been built up had the industry been introduced later than 1676 . The development of screen textile printing began in Japan from the 17th century. The Japanese technique was taken to France where modern flat screen textile printing was initially developed using silk fabric stretched over a wooden frame.

Ergonomics is the scientific discipline concerned with the understanding of interactions among humans and other elements of a system, and the profession that applies theory, Principles, data and methods to design in order to optimize human well-being and overall system performance [2]. Wilson (2000) defined ergonomics as "understanding the theoretical and fundamental aspects of human behaviour and performance in purposeful interacting socio-technical systems, and the application of that understanding interactions of design context of real-systems" [3]. Lee (2005) stated that ergonomics is concerned with promoting compatibility between humans and systems. The commonly highlighted definitions of ergonomics is mainly about the finding relationship between humans, machine systems, health and safety, job design and the work environment [4]. 
In all the available industrial occupations, hand tools are primary tools. A major concern of these industries is the high percentage of disorders that occur annually. In many occupations, some of the major causes of work-related disorders and diseases are due to the use of hand tools.Ergonomically designed hand tools reduce the risk of occupational disorders of the upper limbs. They also provide comfortable work for the workers and give high production rate [5].

Musculoskeletal disorders (MSDs) are currently most critical problems faced by the ergonomists in the workplace. Workplaceinjuries are extremely severe in these types of industries. Poor working conditions and the absence of workers have resulted in a very high incidence of MSDs [6]. Handicraft work is a tough occupation. A number of researchers have studied handicraft work methods and working postures along with the psychosocial aspects of handicraft work [5-15]. The findings of these studies describe work activities where inappropriate working postures are common and work areas not designed properly for work that require unnecessary levels of force.

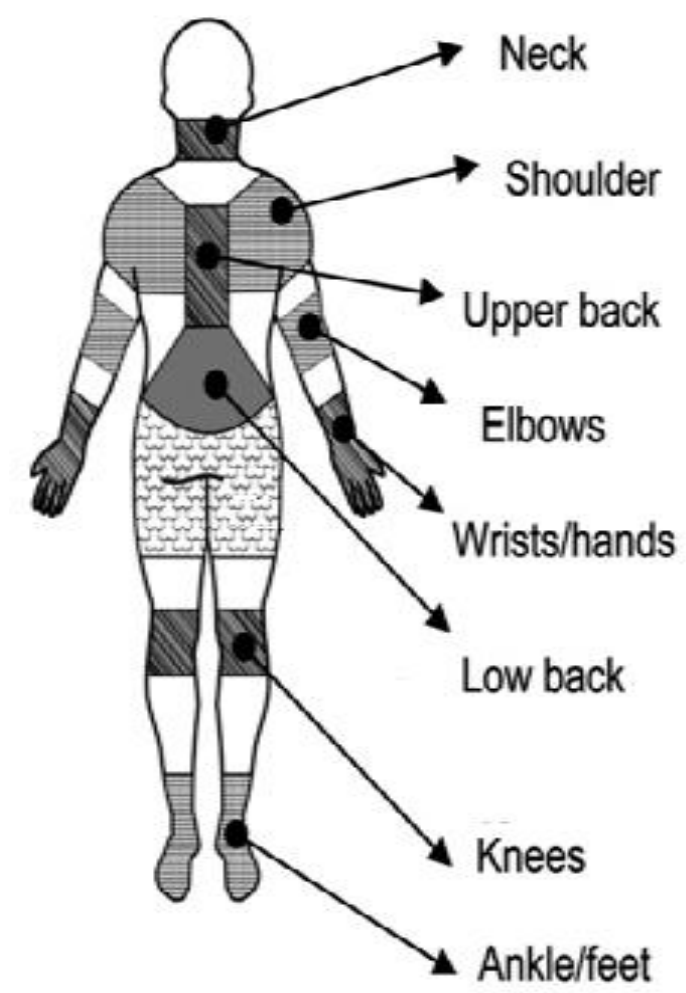

Figure 1. Body regions

Anthropometry studies the dimensions of the human body. It plays an important role in ergonomics, architecture, clothing design and industrial design. Body dimensions of the people living in different countries differ from each other. Body dimensions of the people living in different countries differ from each other. It occurs since people in different countries exhibit difference in nutrition, life style, ethnicity etc. [16]. Figure 1 shows that the various body regions of human. According to Kumar and Das (2012), incorporation of proper anthropometric dimensioning in designing hand tools would provide much effect on health and work efficiency and as a result it would improve the worker's performance and productivity [17]. 


\section{MATERIALS AND METHODS}

This study consisted of two phases, which are explainedbelow:

\subsection{Phase-1:Field Study}

In this phase, survey questionnaire was used for this study. 45 screen printing textile units in Sanganer and Bagru in Jaipur, were selected and 300 male workers were taken into consideration in this study. All the 300 male workers involved in screen printing were interviewed and consequently questionnaires were filled. Based on the videos, photographs, personal interviews and filled survey questionnaires, problems of the workers in textile printing were identified. The questionnaire consisted of three parts including; (a) personal details, (b) Nordic Questionnaire for musculoskeletal disorders and (c) anthropometric dimensions.

\subsection{Phase-2: Hand Tool Design}

In this phase, based on the results of the first phase, designing of screen printing hand tool using anthropometric data.Physical factors taken into consideration in developing new hand tool are using ergonomic principlesadopted from these studies $[5,13,18]$.

\section{RESULTS}

\subsection{Phase-1}

The Figure 2 and Table 1 presents the prevalence of musculoskeletal disorders in different body regions of workers. As Figure 2 shows, the most commonly affected parts are lower back, knee, shoulders and hand.

Table1.Prevalence of musculoskeletal disorders among worker $(\mathrm{N}=300)$

\begin{tabular}{|l|c|c|}
\hline Musculoskeletal Disorders & $\begin{array}{c}\text { No. of } \\
\text { Workers }\end{array}$ & $\begin{array}{c}\text { Percentage of } \\
\text { Workers (\%) }\end{array}$ \\
\hline Headache & 174 & 58 \\
\hline Stiffness in neck & 198 & 66 \\
\hline Low back pain & 237 & 79 \\
\hline Shoulder pain & 222 & 74 \\
\hline Fore-arm pain & 183 & 61 \\
\hline Soreness in elbow & 195 & 65 \\
\hline Stiffness in knee & 201 & 67 \\
\hline Hand/wrist pain & 228 & 76 \\
\hline Stiffness in finger & 204 & 68 \\
\hline
\end{tabular}

In this study the prevalence of musculoskeletal disorders among workers were $79 \%$ for the low back pain due to improper ergonomically designed screen printing hand tool. Screen printing workers as they have to reach out across the wide table to place the hand tool at the extreme end, and then again reach back to place, in an unbroken rhythm that maintains the pace of work. Other 
musculoskeletal disorders among workers were $76 \%$ for the hand/wrist pain, and $74 \%$ for shoulder pain. About $66 \%$ of the workers suffered from neck pain.

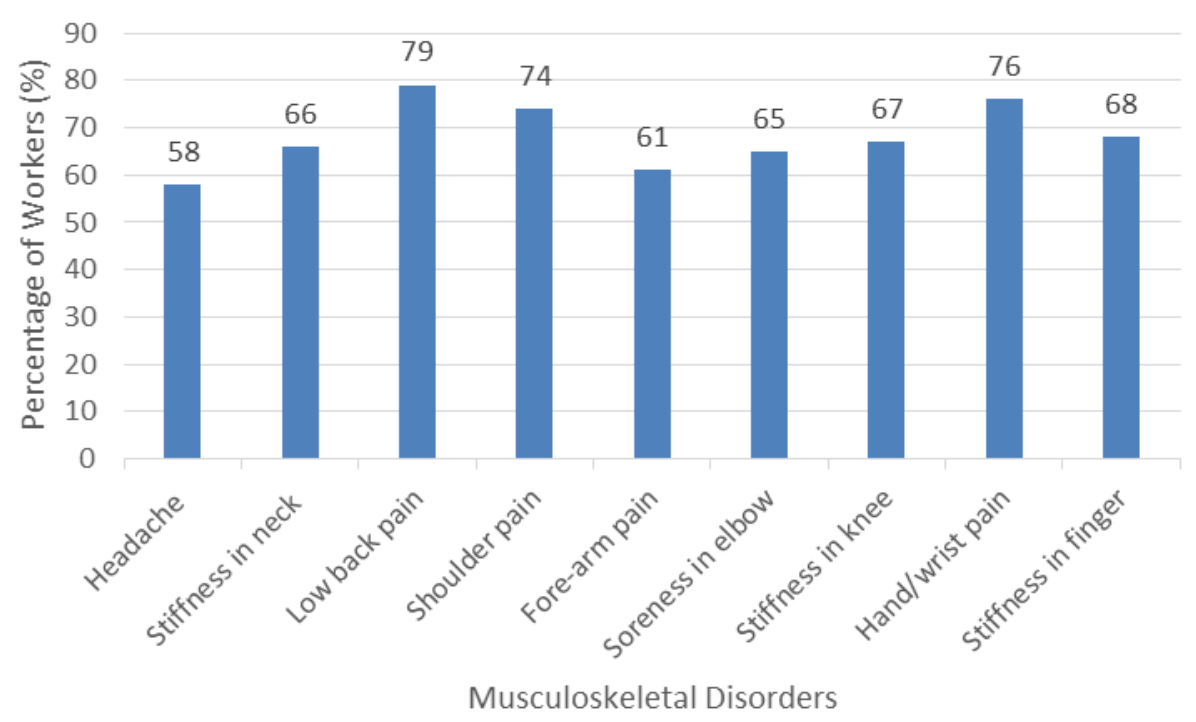

Figure 2.Prevalence of musculoskeletal disorders among worker $(\mathrm{N}=300)$

Survey results shows that $66 \%$ workers want to improvement in working conditions, Other result shows that more than $59 \%$ of workers do not satisfied with their working environments. Nearly $44 \%$ of workers work on screen printing table more than 20 minutes in single instants. $40 \%$ workers want to redesign the hand tool because of they are not comfortable with exiting hand tools. Most of workers suffer from various symptoms problems which is not good for long time, so that workers want to some design improvements in their exiting hand tool.

\subsection{Phase-2}

Based on ergonomics principles of hand tool design, and anthropometric dimensions of the printing workers, prototypes for screen printing hand tool were developed in order to minimize the musculoskeletal disorder of screen printing workers. It also increases the productivity of the firms and decreases the various body pains such as low back pain, soreness in arms, and pain in shoulder. Table 2 presents $5^{\text {th }}$ percentiles, $50^{\text {th }}$ percentiles, and $95^{\text {th }}$ percentiles of the screen textile printing male workers population studied.

Table $2.5^{\text {th }}, 50^{\text {th }}$, and $95^{\text {th }}$ percentiles of the male workers population studied

\begin{tabular}{|l|c|c|c|}
\hline Parameter & $\begin{array}{c}\mathbf{5}^{\text {th Percentile }} \\
\text { (in Centimetres) }\end{array}$ & $\begin{array}{c}\mathbf{5 0}^{\text {th }} \text { Percentile } \\
\text { (in Centimetres) }\end{array}$ & $\begin{array}{c}\mathbf{9 5}^{\text {th }} \text { Percentile } \\
\text { (in Centimetres) }\end{array}$ \\
\hline Hand length & 16.745 & 18.65 & 20 \\
\hline Upper arms & 24.075 & 26.45 & 29.85 \\
\hline Lower arms & 24 & 26 & 29 \\
\hline Shoulders width & 38.03 & 42 & 45 \\
\hline Standing height & 159.06 & 169 & 174.765 \\
\hline Grip diameter(inner) & 3 & 3.6 & 5 \\
\hline
\end{tabular}


International Journal of Recent advances in Mechanical Engineering (IJMECH) Vol.4, No.2, May 2015

\begin{tabular}{|l|c|c|c|}
\hline Grip diameter(outer) & 5.915 & 7.5 & 10.51 \\
\hline Palm length & 8.83 & 11 & 12.6 \\
\hline Palm Width & 4.5 & 10.05 & 12 \\
\hline Thumb length & 4.545 & 6.85 & 7.97 \\
\hline Thumb breadth & 2 & 2.3 & 3 \\
\hline Fist length & 7.715 & 9 & 10.485 \\
\hline Wrist breadth & 5.3 & 6.25 & 7.185 \\
\hline Wrist thickness & 3 & 3.65 & 5 \\
\hline Wrist circumference & 15 & 16.5 & 18.255 \\
\hline Chest breadth & 26.575 & 29.75 & 34 \\
\hline Waist height(Leg) & 90.3 & 101 & 104 \\
\hline Fingers Length & 6.215 & 7.9 & 9. \\
\hline Hand breadth & 7.8 & 8.95 & 10 \\
\hline Shoulders Height & 136 & 145 & 153.8 \\
\hline
\end{tabular}

\subsection{Design Parameters of Hand Tool}

Hand tools are used in most of industrial works to enhance the physical capabilities of workers. However, poor design and excessive use of hand tools were found to be the major cause of workrelated injuries associated with cumulative trauma disorder. Deteriorate on workers' health and their suffering are inaccessible whilst economic lost from worker remedy and compensation is enormous. To prevent and alleviate cumulative trauma disorder, appropriate tools designed and used for workers and their tasks are needed. In order to design a hand tool, one needs to calculate the necessary dimensions of a hand tool which in turn depend upon comfort conditions for a worker, Studies focusing the overall comfort of the worker. Data significant for a hand tool are discussed below:

- Task Considerations

- User Considerations

- Grip and Handle Considerations

On the basis of above consideration, designed the hand tool for screen printing workers. Calculate handlebar length for designing of new hand tool using triangular method and anthropometry data. Table 3 shows determined anthropometric values for hand tool of screen printing textile industries.

Table 3. Values for hand tool of screen printing

\begin{tabular}{|l|c|}
\hline \multicolumn{1}{|c|}{ Particulars } & $\begin{array}{c}\text { Dimension } \\
\text { (in Centimetres) }\end{array}$ \\
\hline Length of handle & 11 \\
\hline Handle diameter & 3 \\
\hline Length of handle bar & 97.02 \\
\hline Width between both handlebar & 41.5 \\
\hline
\end{tabular}


These values based on anthropometric data taken average of $5^{\text {th }}$ and $95^{\text {th }}$ percentile considering the design of hand tool for screen textile printing industries. Figure 3 shows the hand tool for screen textile printing.

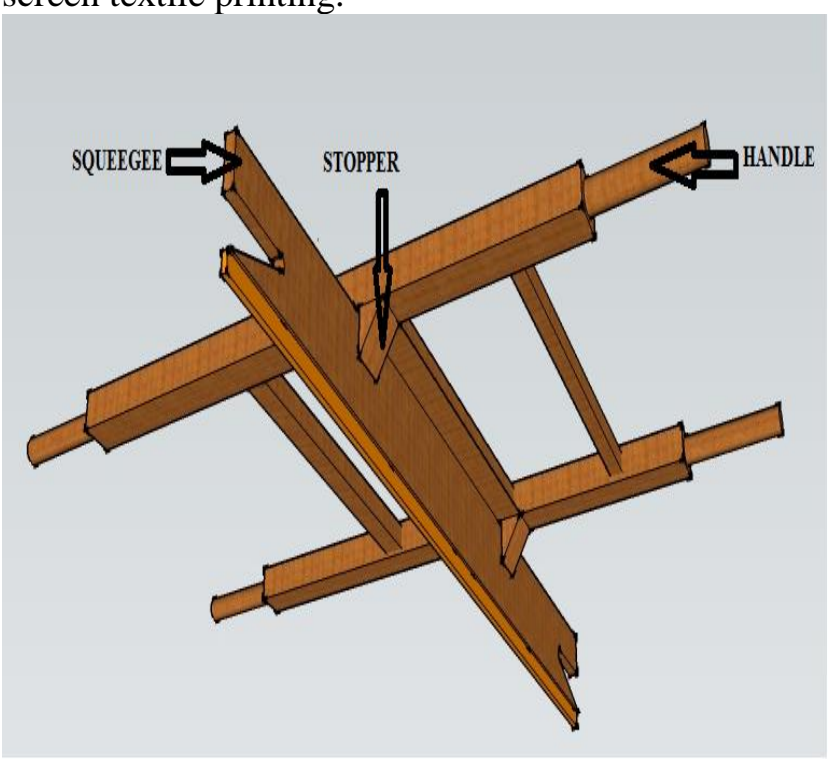

(a) Hand tool design in Google Sketch up software

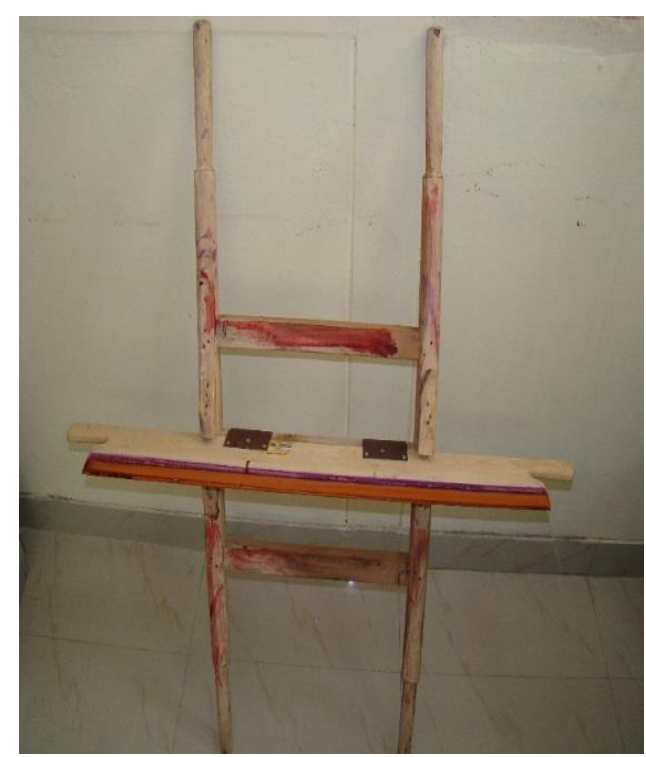

(b) Physical hand tool

Figure 3. Hand tool for screen textile printing

\subsection{Validation and Testing}

After ergonomically design of hand tool for screen textile printing, generated feedback questionnaire and gone to printing industries, work has to done by workers two to three months after that taken feedback of the workers. The sample size of survey is 100. The Figure 4 presents the prevalence of musculoskeletal disorders in different body regions of workers after using new hand tool.As Figure 4 shows, the prevalence of musculoskeletal disorders among workers were $29 \%$ for the low back pain.Other musculoskeletal disorders among workers were $31 \%$ for the hand/wrist pain, and 33\% for shoulder pain. About $46 \%$ of the workers suffered from neck pain.

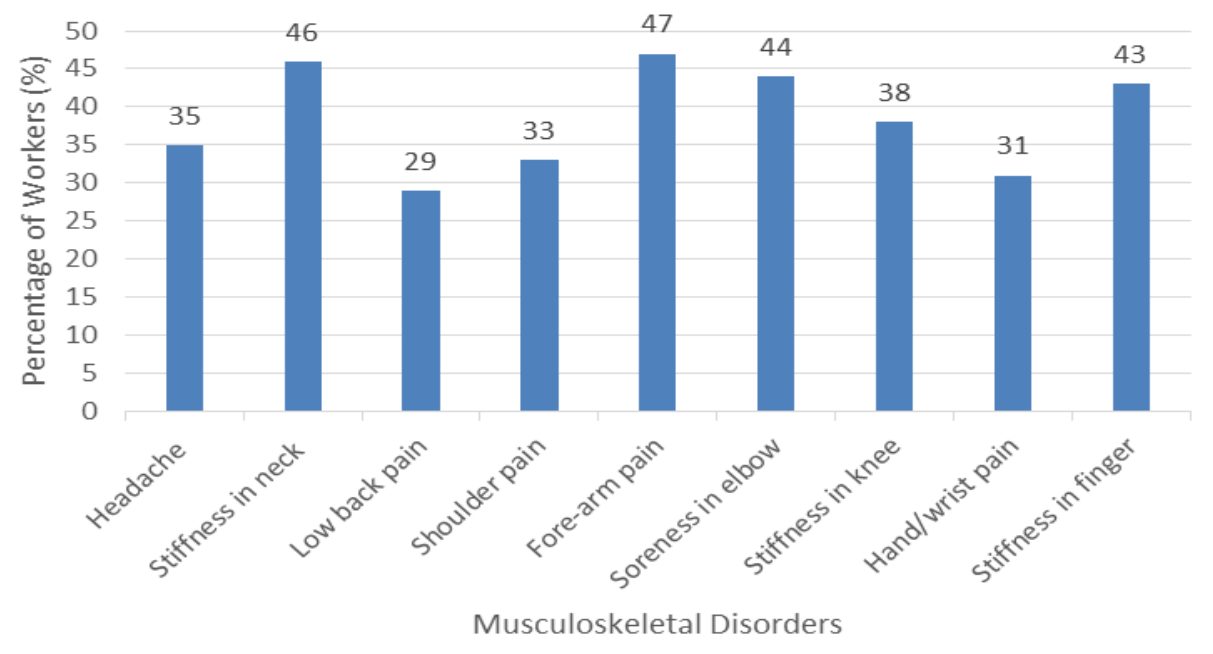

Figure 4. Prevalence of musculoskeletal disorders among worker $(\mathrm{N}=100)$ 


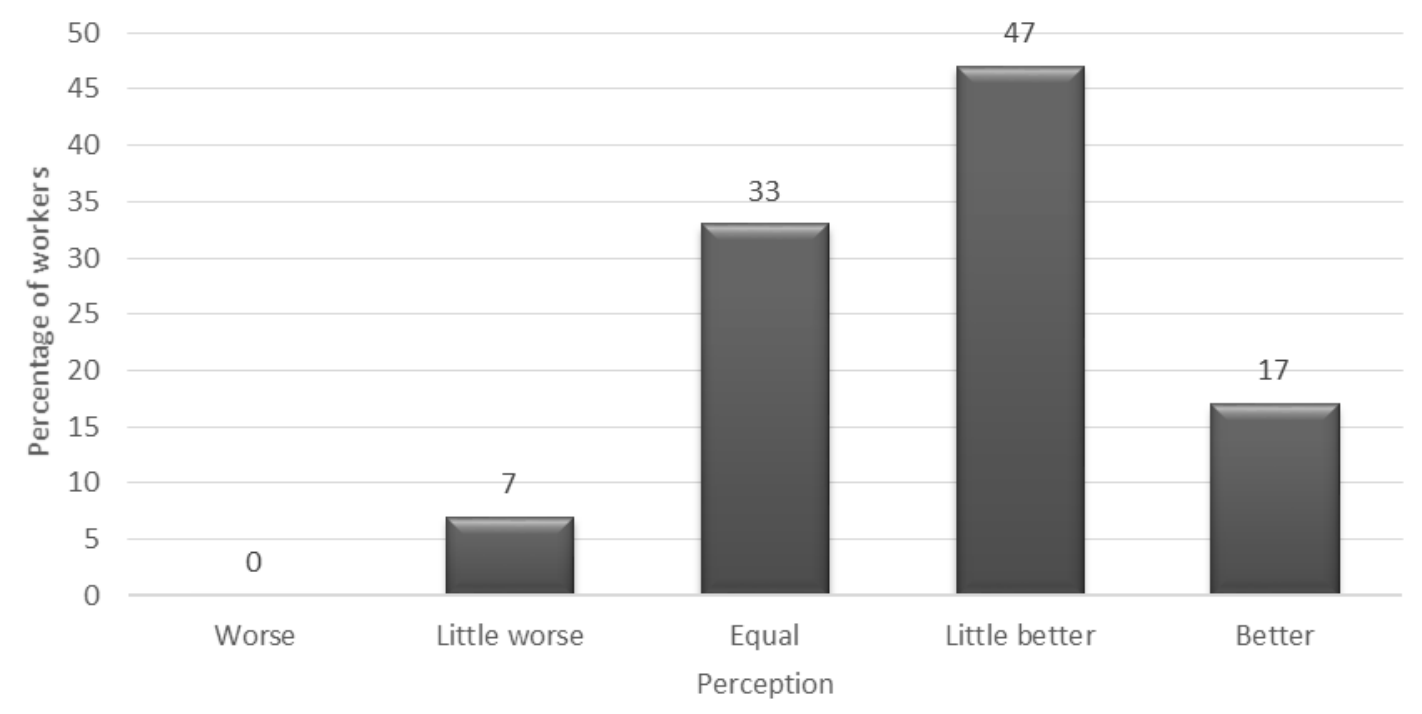

Figure 5. Workers' judgment about working with new and traditional hand tool $(\mathrm{N}=100)$

Most of the screen textile printing workers participated in the second phase of this study found their working postures with new screen textile printing hand toolis better and reported comfort. Workers believed that the new hand tool were better than the traditional hand tool (Figure 5). In $64 \%$ of the cases, the new hand tool was evaluated little better or better and the comfort was increased.

\section{Conclusion}

Workers found their working postures with new hand tool good and reported comfort. In this study, the musculoskeletal disorders were reduced by developing a redesign hand tool.The new ergonomically designed screen printing hand tool was found to be applicable and acceptable for the screen printing workers. Results shows that low back pain was the big problem of screen printing workers which have been reduced to $29 \%$ from $75 \%$,pain in shoulder have been reduced $33 \%$ from $74 \%$. However, further study is needed to make appropriate revisions to the ergonomically designed hand tools based on quantitative measures of musculoskeletal loading. 


\section{REFERENCES}

[1] ASA and Associates (ASAA). (2014) A Brief Report on Textile Industry in India [online]. New Delhi. http://www.asa.in/pdf/surveys_reports/Textile-Industry-in-India.pdf. (Accessed 02 November 2014).

[2] J. Dul and W. P. Neumann, "Ergonomics contributions to company strategies", Applied Ergonomics, Vol. 40, No. 4, pp. 745-752, 2009.

[3] J. R. Wilson, "Fundamentals of ergonomics in theory and practice", Applied Ergonomics, Vol. 31, No.6, pp. 557-567, 2000.

[4] K.S. Lee, "Ergonomics in total quality management: how can we sell ergonomics to management?" Ergonomics, Vol. 48, No. 5, pp. 547-558, 2005.

[5] M.Motamedzade, A. Choobineh, M. A. Mououdi, andS. Arghami, "Ergonomic design of carpet weaving hand tools", International Journal of Industrial Ergonomics, Vol. 37, No. 7, pp. 581-587, 2007.

[6] A. Choobineh, M. Hosseini, M. Lahmi, R. Khani, and H. Shahnavaz,"Musculoskeletal problems in Iranian hand-woven carpet industry: guidelines for workstation design", Applied Ergonomics, Vol. 38, No. 5, pp. 617-624, 2007.

[7] D. C.Metgud, S. Khatri, M. G. Mokashi and P. N. Saha, "An ergonomic study of woman worker in a woollen textile factory for identification of health related problems", Indian Journal of Occupational and Environmental Medicine, Vol. 12, No. 1, pp. 14-19, 2008.

[8] J. Kaljun and B. Dolsak, "Ergonomic design knowledge built in the intelligent decision support system”, International Journal of Industrial Ergonomics, Vol. 42, No. 1, pp. 162-171, 2012.

[9] C. Arunesh and C. Pankaj, "Ergonomic design of hand tool (screwdriver) for Indian worker using comfort predictors a case study", International Journal of Advanced Engineering Technology, Vol. 2, No. 4, pp. 231-238, 2011.

[10] P.Areeudomwong, R. Puntumetakul, D. B. Kaber, S. Wanpen , N. Leelayuwat and U. Chatchawan, "Effects of handicraft sitting postures on lower trunk muscle fatigue", Ergonomics, Vol. 55, No. 6, pp. 693-703, 2012.

[11] M. L. Meena, G. S. Dangayach and A. Bhardwaj "Impact of Ergonomic Factors in Handicraft Industries", Proceeding of International Conference on Mechanical, Production and Automobile Engineering (ICMPAE'2011), Pattaya, Thailand, 17th -18th December, 2011, pp. 247-249.

[12] M. L. Meena, G.S. Dangayach and A. Bhardwaj, "Occupational Risk Factor of Workers in the Handicraft Industry: A Short Review", International Journal of Research in Engineering and Technology, Vol. 1, No. 3, pp. 194-196, 2012.

[13] M. L. Meena, G.S. Dangayach and A. Bhardwaj, "Measuring anthropometric data for designing hand tools in handicraft industries", International Journal of Process Management and Benchmarking, Vol.3, No.3, pp.334 - 351, 2013.

[14] M. L. Meena, G.S. Dangayach and A. Bhardwaj, "Measuring Quality of Work Life Among Workers in Handicraft Industries of Jaipur", International Journal of Industrial and Systems Engineering, Vol.17, No.3, pp.376 - 390, 2014.

[15] M. L. Meena, G. S. Dangayach and A. Bhardwaj, "Investigating Ergonomic Issues among workers in Hand Block Textile Printing Industries", International Journal Business and Systems Research, Vol.8, No.4, pp.392 - 401, 2014.

[16] K. N. Dewangan, C. Owary and R. K. Datta,"Anthropometry of male agricultural workers of northeastern India and its use in design of agricultural tools and equipment”, International Journal of Industrial Ergonomics, Vol. 40, No. 5, 560-573, 2010.

[17] G. S. Kumar and A. Das, "Analysis and ergonomic improvement of working postures in cast house work station using JACK modelling”, International Journal of Human Factors Modelling and Simulation, Vol. 3, No. 1, 16-31, 2012.

[18] M. You, G. Lyu. and I. Chen, "An ergonomic approach to oyster knife design and evaluation a preliminary result", National Yunlin University of Science and Technology, Department of Industrial Design Yunlin, Taiwan, pp 2427-2435, 2009. 
International Journal of Recent advances in Mechanical Engineering (IJMECH) Vol.4, No.2, May 2015

\section{Authors}

M. L. Meena is Assistant Professor in Department of Mechanical Engineering in Malaviya National Institute of Technology (MNIT) Jaipur. He was graduated in Mechanical Engineering from University of Rajasthan, Jaipur in the year 2005. He obtained Master's degree in Manufacturing System Engineering from MNIT Jaipur. He did his Ph.D. from MNIT Jaipur. His research areas are ergonomics and productivity engineering. He has published 09 research papers in various International Journals. He has 08 years of Teaching and Industrial experience.

G. S. Dangayach is Professor in Department of Mechanical Engineering in Malaviya National Institute of Technology (MNIT) Jaipur. He was graduated in Mechanical Engineering from M.B.M. Engineering College Jodhpur in the year 1985. He obtained Master's degree in Production Engineering from Indian Institute of Technology (IIT), Delhi. He earned his Doctorate in Industrial Engineering also at IIT, Delhi. He has published 124 research papers in various National and International Journals. He is Guest Editor of three International Journals viz. Production planning \& Control (PPC), International Journal of Manufacturing Technology \& Management (IJMTM), International Journal of Business Performance Management (IJBPM). He is Reviewer of Eighteen International Journals. He is Visiting Professor at School of Management, Asian Institute of Technology (AIT) Bangkok, IIM Khozikode, IIM Shillong, \& Leeds-Met India, Bhopal. He delivered several Invited Lectures/Key note addresses in India \& abroad. He has 29 years of Teaching and Industrial experience. 